\title{
Transmission Electron Microscope Studies on the Behaviours of Dislocations during Creep Deformation of Copper Single Crystals*
}

\author{
By Tadashi Hasegawa**, Hiroshi Sato*** \\ and Seiichi Karashima**
}

\begin{abstract}
A series of experiments has been carried out by the present authors by means of the Berg-Barrett method, the etch-pit technique, and transmission electron microscopy to make clear the substructure developed in copper single crystals during high temperature creep. In this paper the results obtained on the dislocation structures by transmission electron microscopy are reported. The dislocation motion and the creep rate in steady-state creep is also discussed on the basis of the experimental results. The main conclusions obtained are as follows :

(1) The subgrains surrounded by "large angle sub-boundaries" observed by the Berg-Barrett method and the etch-pit technique are further divided into smaller ones by "small angle sub-boundaries" which can be detected only by transmission electron microscopy.

(2) In steady-state creep mobile dislocations are emitted mainly from the small angle sub-boundaries. After gliding through subgrains, the mobile dislocations are absorbed into the neighbouring small angle sub-boundaries to become immobile. The mean free path of the mobile dislocations is thus limited by the small angle sub-boundaries, being a few $\mu$ to $10 \mu$ and $10 \mu$ to a few tens of microns for the primary edge and the primary screw dislocations, respectively.

(3) Steady-state creep rates can be explained quantitatively from the results by transmission electron microscopy, on the assumption that the glide motion of screw dislocations having super jogs is the rate-controlling process. The heights of the super jogs are $\sim 20 \mathrm{~b}$ and $\sim 6 \mathrm{~b}$ and their spacings are $\sim 0.4 \mu$ and $\sim 0.2 \mu$ at $745^{\circ} \mathrm{C}$ and $610^{\circ} \mathrm{C}$, respectively.
\end{abstract} (Received February 3, 1970)

\section{Introduction}

Many investigations ${ }^{(1) \sim(8)}$ by means of transmission electron microscopy have been done to make clear the process of substructure formation in high-temperature creep deformation. At present it is widely accepted that a well-defined substructure is formed in metals and alloys during high temperature creep. Few systematic works, however, have so far been reported with regard to the relation between the substructure formation and the creep mechanisms.

A series of experiments has been carried out by the present authors with a view to making clear the relation between the high-temperature creep deformation and the substructure formation in copper single crystals. In those works the substructure was examined by means of the X-ray Berg-Barrett method, the etch-pit technique, and transmission electron microscopy.

In the present paper the results obtained on the dislocation structures by transmission electron microscopy are described. The dislocation motion and the creep rate in steady-state creep are also discussed on the basis of the experimental results obtained by three kinds of techniques mentioned above. Results obtained by the Berg-Barrett $\operatorname{method}^{(9)}$ and the etch-pit technique ${ }^{(10)}$ have been reported elsewhere.

* The major part of this paper was originally published in Japanese in J. Japan Inst. Metals, 33 (1969), 1239 and 1333.

** Department of Materials Science, Faculty of Engineering, Tohoku University, Sendai, Japan.

**** Graduate School, Tohoku University, Sendai. Present address : Kamaishi Works, Nippon Steel Corporation, Kamaishi, Japan.

\section{Experimental Procedure}

Single crystals used throughout the experiments were prepared from high-purity copper $(99.999 \%)$. They were produced in vacuum $\left(\sim 10^{-5} \mathrm{~mm} \mathrm{Hg}\right)$ by the Bridgman method using a graphite hard-mould. The crystallographic orientation as well as the shape and size of the specimens are the same as those used in X-ray studies ${ }^{(9)}$. The tensile axis lies in the centre of the stereographic triangle. The primary slip plane, (111), is normal to the specimen surface, making an angle of about 45 degrees with the tensile axis. The primary slip direction, [ $\overline{1} 01]$, is parallel to the specimen surface.

All the specimens were subjected to cyclic annealing ${ }^{(11)}$ (12) in vacuum $\left(\sim 2 \times 10^{-5} \mathrm{~mm} \mathrm{Hg}\right)$ in the temperature

(1) F.Garofalo , L.Zwell, A.S.Keh and S. Weissmann : Acta Met., 9 (1961), 721.

(2) P. Feltham and R. A. Sinclair : J. Inst. Metals, 91 (1962 63) 235.

(3) A. S. Keh and S. Weissmann : Electron Microscopy and Strength of Crystals, Interscience, (1963), p. 231.

(4) C. R. Barrett : Acta Met., 13 (1965), 1088.

(5) G. J. Richardson, G. M. Sellars and M. J. McG. Tegart : Acta Met., 14 (1966), 1225.

(6) C. R. Barrett, W.D. Nix and O.D. Sherby : Trans. ASM, 59 (1966), 3.

(7) F.H. Hammad and W.D. Nix : Trans. ASM, $59(1966), 94$.

(8) A.H.Clauer, B.A.Wilcox and J.P.Hirth : Acta Met., 18 (1970), 381.

(9) T. Hasegawa, H. Sato and S. Karashima : J. Japan Inst. Metals, 33(1969), 179 ;Trans. JIM, 11(1970), 94.

(10) T. Hasegawa, R. Hasegawa and S. Karashima : J. Japan Inst. Metals, 33 (1969), 185 ; Trans. JIM, 11 (1970), 101

(11) S. Kitajima, M. Ohta and H. Kaieda : J. Japan Inst. Metals, 32 (1968), 164.

(12) T. Hasegawa, Y.Ishii and S. Karashima: J.Japan Inst. Metals, 33 (1969), 1337 ; Trans. JIM, to be published. 
range between $1050^{\circ}$ and $750^{\circ} \mathrm{C}$ for about 40 cycles before creep tests. The dislocation density within subgrains and the subgrain size after this treatment were $10^{3} \sim 10^{4} / \mathrm{cm}^{2}$ and several hundred microns, respectively.

Creep tests were done in argon atmosphere at $0.75 T_{m}$ $=745^{\circ} \mathrm{C}$ and $0.65 T_{m}=610^{\circ} \mathrm{C}\left(T_{m}\right.$ : the melting temperature in degrees Kelvin). Applied shear stresses on the primary slip plane (111) were $180 \mathrm{~g} / \mathrm{mm}^{2}$ and 340 $\mathrm{g} / \mathrm{mm}^{2}$ at $745^{\circ} \mathrm{C}$ and $610^{\circ} \mathrm{C}$, their corresponding steadystate creep rates being about $0.03 \% / \mathrm{hr}$ at $745^{\circ} \mathrm{C}$ and $0.005 \% / \mathrm{hr}$ at $610^{\circ} \mathrm{C}$.

After several creep strains were given, specimens were cooled rapidly to room temperature under the loaded condition; the cooling rate was about $110^{\circ} \mathrm{C} / \mathrm{min}$ in the high temperature range. Thin foils with the primary slip plane, (111), parallel to the plane of the foil were prepared from the specimens by means of strain-free cutting and electro-chemical polishing. Their average thickness was about $1.5 \sim 2.0 \mu$. They were examined with a $500 \mathrm{kV}$ electron microscope.

\section{Experimental Results and Discussion}

Althongh the subgrain size in a specimen after creep was larger at $745^{\circ} \mathrm{C}$ than at $610^{\circ} \mathrm{C}$, no other essential differences in substructures were observed at both temperatures. Therefore, the results will be given mainly on the specimens deformed at $745^{\circ} \mathrm{C}$.

\section{Arrangements and density of dislocations}

Photo. 1 shows dislocation arrangements in a wide area of the specimen after creep at $745^{\circ} \mathrm{C}$ to $10.9 \%$ strain (in steady-state creep). Stereographic projection by the photograph shows the crystallographic orientation in the thin foil ; 111, 101 and $1 \overline{2} 1$ represent the direction of the normal to the primary slip plane, the primary slip direction, and the direction of the lattice rotation axis in the deformation band, respectively. From the spacing between sub-boundaries and the sub-boundaries indicated by $\mathrm{L}$ are identified as sub-boundaries of large misfit angle

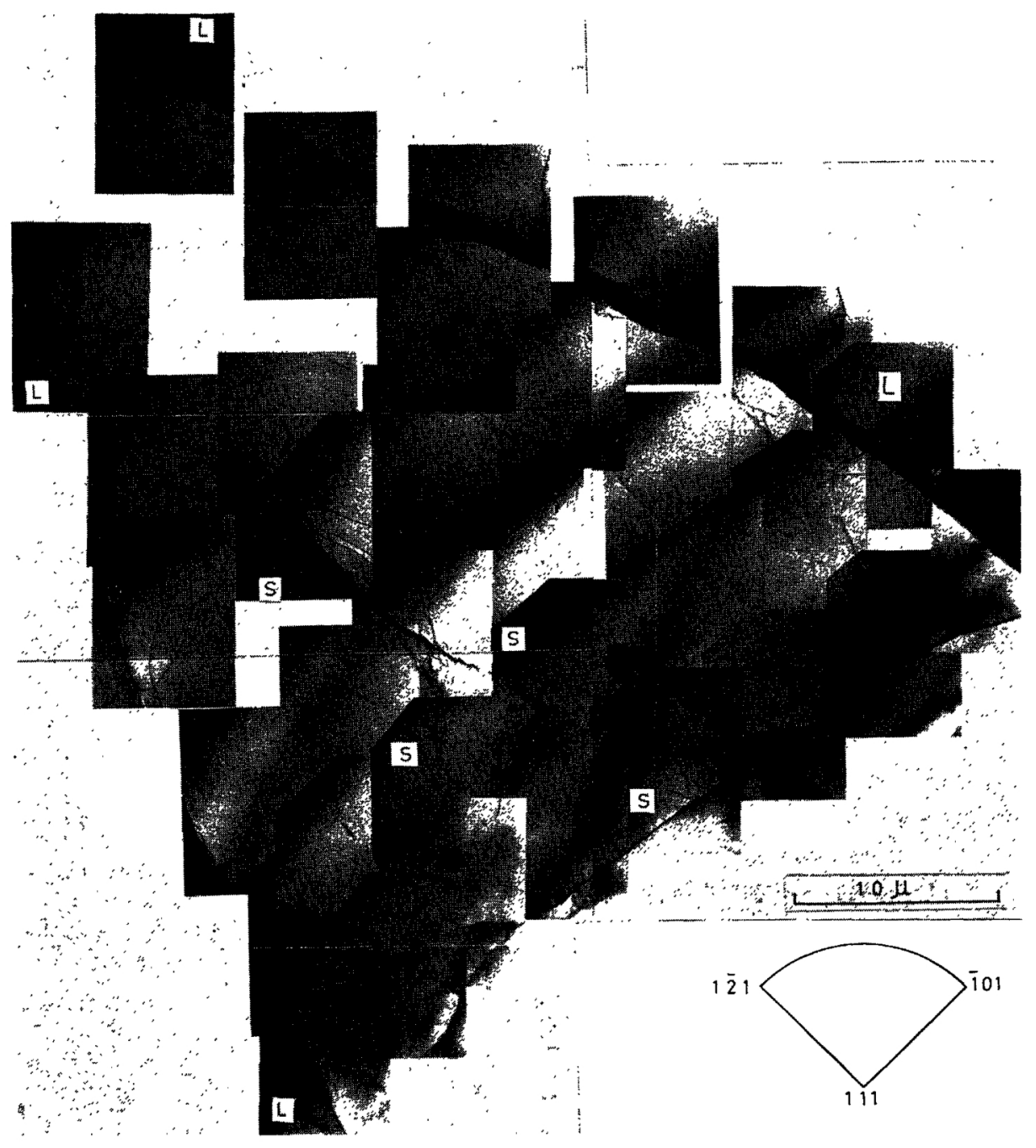

Photo. 1 Transmission electron micrograph showing the dislocation arrangements in a wide area of a specimen after creep at $745^{\circ} \mathrm{C}$ to $10.9 \%$ strain (in steady-state creep). The sub-boundaries indicated by $L$ are large angle sub-boundaries which can be observed also by the Berg-Barrett method and the etch-pit technique. Those indicated by $\mathrm{S}$ are small angle sub-boundaries detected only by transmission electron microscopy. Orientation relationship in the thin foil is shown by a stereographic projection; $111, \overline{1} 01$ and $1 \overline{2} 1$ represent the direction of the normal to the primary slip plane, the primary slip direction, and the direction of the lattice rotation axis in deformation band, respectively. 
which can also be observed by the Berg-Barrett method ${ }^{(9)}$ and the etch-pit technique ${ }^{(10)}$. On the other hand, the sub-boundaries indicated by $\mathrm{S}$ may be sub-boundaries of small misfit angle which can be detected only by transmission electron microscopy. They are called hereafter "large angle sub-boundaries" and "small angle subboundaries".

A typical example of transmission electron micrographs showing the distribution of small angle sub-boundaries is given in Photo. 2. As seen in Photo. 2, most of the sub-boundaries are nearly parallel to the (101)-trace ${ }^{\dagger}$. Hence, they are considered to be tilt boundaries consisting mainly of edge dislocations. They are about $10 \mu$ in length and are distributed with an average spacing of several microns.
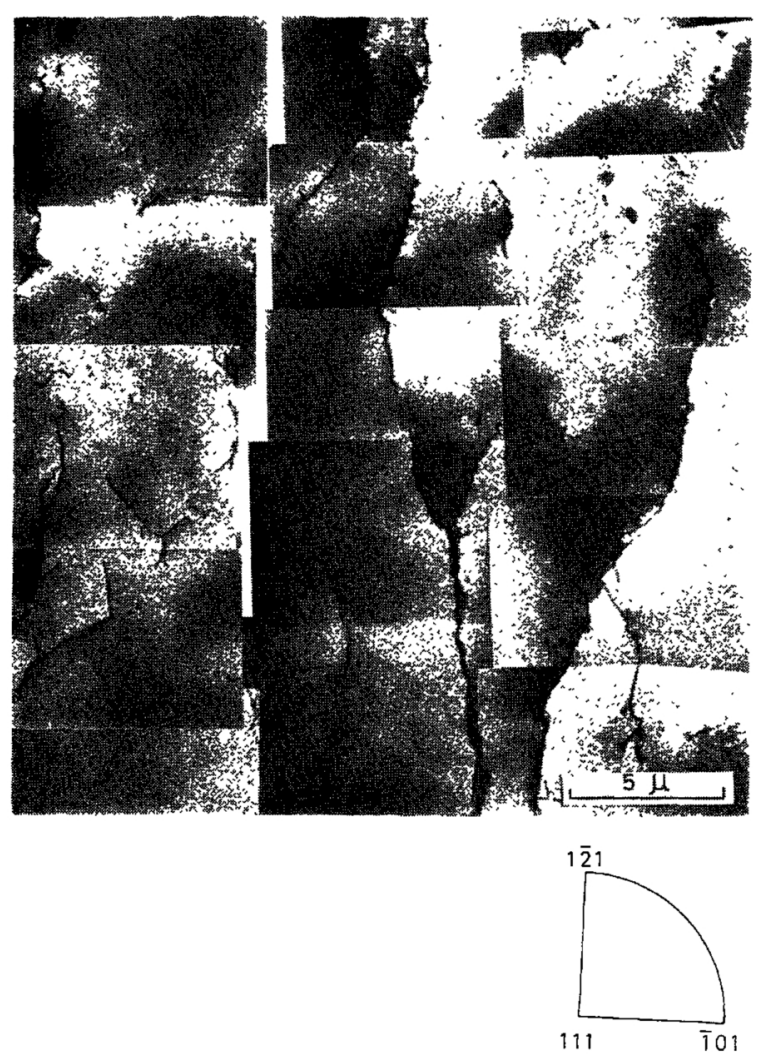

Photo. 2 Transmission electron micrograph showing the random distribution of sub-boundaries parallel to (101)-trace in a specimen after creep at $745^{\circ} \mathrm{C}$ to $5.1 \%$ strain (in transient creep).

As seen in Photo. 1, many dislocations are observed in the vicinity of large and small angle sub-boundaries. Within subgrains, however, the dislocation density is very low ${ }^{\dagger t}$; the density of dislocations not associated with both kinds of sub-boundaries is $3 \times 10^{6}$ to $5 \times 10^{6}$ $/ \mathrm{cm}^{2 \dagger \dagger \dagger}$. The dislocation density of $\sim 3 \times 10^{6} / \mathrm{cm}^{2}$ was

† In this paper, the term " $(h k l)$-trace" is used in the sense that the $(h k l)$-trace is the direction of the intersection of the $(h k l)$ plane with the foil surface.

i† In the present experiments, a tilting device was used to measure dislocation density as exactly as possible.

$+\uparrow \dagger$ During the observation with an electron microscope glide motion of dislocations was sometimes observed on the slip planes inclining to the foil surface. The average thickness of the thin foils was estimated at 1.5 to $2.0 \mu$ from the projected widths of the slip traces. obtained at the beginning of steady-state creep by the etch-pit technique ${ }^{(10)}$. These two values agree with each other, though the dislocations associated with small angle sub-boundaries are included in the dislocation density measurements by the etch-pit technique. This agreement may be due to the fact that the small angle subboundaries are not formed so much at the beginning of steady-state creep as revealed by transmission electron microscopy.

Dislocation density within subgrains and spacings of small angle sub-boundaries remained almost constant in steady-state creep. Mobile dislocations in steady-state creep are considered to be isolated ones observed within subgrains. It is reasonable that mobile dislocation density remains almost constant in steady-state creep, because the creep rate is constant in this stage.

From the facts mentioned above the dislocation density of $\sim 3 \times 10^{6} / \mathrm{cm}^{2}$, which was obtained at the beginning of steady-state creep by the etch-pit technique, will be used as the mobile dislocation density at $745^{\circ} \mathrm{C}$ in the following discussion. In the same way we obtain the mobile dislocation density of $\sim 5 \times 10^{6} / \mathrm{cm}^{2}$ for creep at $610^{\circ} \mathrm{C}$.

\section{Origin of apparent lattice twisting}

In X-ray studies ${ }^{(9)}$ apparent lattice twisting about the [1리-axis was detected on the (111)-plane within subgrains with a period of about $10 \mu$. The increase in the twist angle was one of the most remarkable structural changes during steady-state creep.

On the other hand, the dislocation density within subgrains was found to increase during steady-state creep by the etch-pit technique ${ }^{(10)}$. Etch-pit observations, however, showed that the distribution of etch pits was random within subgrains. Such a random distribution of dislocations cannot cause the lattice twisting mentioned above. Hence, the other cause of the apparent lattice twisting of (111)-plane should be pursued.

As stated in the foregoing section, it was revealed by transmission electron microscopy that tilt-type small angle sub-boundaries are distributed randomly with an average spacing of several microns. It is reasonably concluded that the apparent lattice twisting of the (111)plane about the [1피]-axis is caused by this random distribution of the small angle sub-boundaries. This conclusion is not contradictory to the experimental facts obtained by the Berg-Barrett method ${ }^{(9)}$ that the lattice twisting is detected on the (111)-plane and not on the (I01)-plane.

Table 1 gives the apparent twist angle ${ }^{(9)}$ and the dislocation density obtaind by the etch-pit technique ${ }^{(10)}$ in steady-state creep. From the table it is clearly seen

Table 1 Relation between the apparent twist angle and the dislocation density within subgrains surrounded by large angle sub-boundaries in steady-state creep $\left(T=745^{\circ} \mathrm{C}, \tau=180 \mathrm{~g} / \mathrm{mm}^{2}\right)$

\begin{tabular}{c|c|c}
\hline $\begin{array}{c}\text { Greep time } \\
(\mathrm{hr})\end{array}$ & $\begin{array}{c}\text { Apparent twist angle } \\
(\text { min of arc) }\end{array}$ & $\begin{array}{c}\text { Dislocation } \\
\text { density }\left(\mathrm{cm}^{-2}\right)\end{array}$ \\
\hline 50 & $\sim 3$ & $\sim 5 \times 10^{6}$ \\
200 & $\sim 5$ & $\sim 1 \times 10^{7}$ \\
\hline
\end{tabular}


that they increase almost in parallel with each other. The dislocation density within subgrains and spacings of small angle sub-boundaries remained unchanged during steady-state creep. Therefore, it is concluded that the increase in dislocation density observed by the etch-pit technique is due to the increase in dislocation density in small angle sub-boundaries.

The mobile dislocation density remains constant during steady-state creep as mentioned in the foregoing section. On the other hand, the dislocation density in small angle sub-boundaries increases as shown above. These facts suggest that some kinds of the dislocation multiplication should occur in steady-state creep.

\section{Role of small angle sub-boundaries as donors and recipients of mobile dislocations}

Photos. 3 and 4 show the dis'ocation distribution in the vicinity of small angle sub-boundaries in the specimens after creep at $745^{\circ} \mathrm{C}$ to $10.9 \%$ strain and at $610^{\circ} \mathrm{C}$ to $9.5 \%$ strain (in steady-state creep), respectively. In the
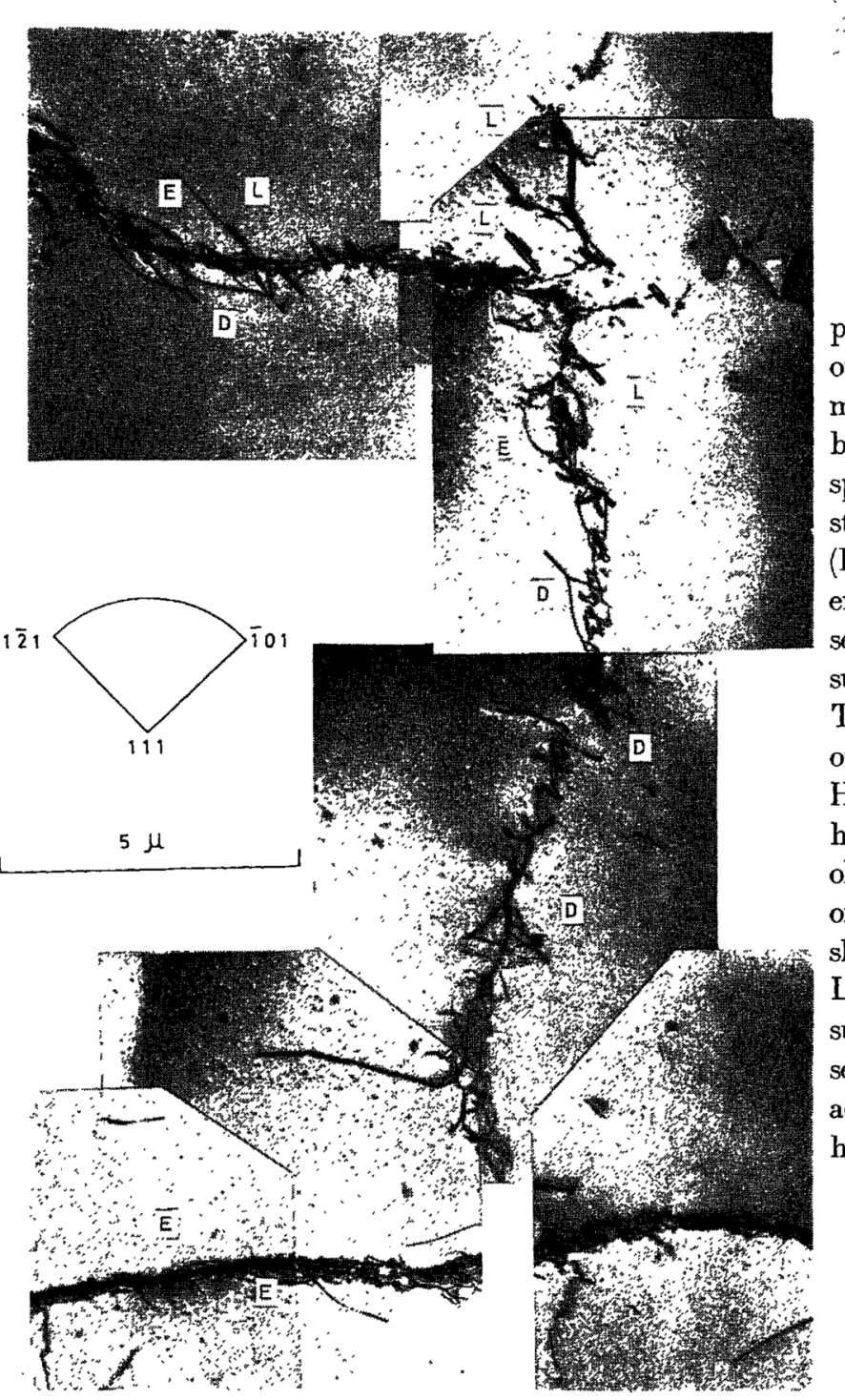

Photo. 3 Transmission electron micrograph showing dislocations bowing out from sub-boundaries (for example, E), dislocations having dipoles (D), and dislocation loops $(\mathrm{L})$ in the vicinity of the sub-boundaries $\left(T=745^{\circ} \mathrm{C}, \tau=180\right.$ $\mathrm{g} / \mathrm{mm}^{2}$, and $\varepsilon=10.9 \%$ in steady-state creep).

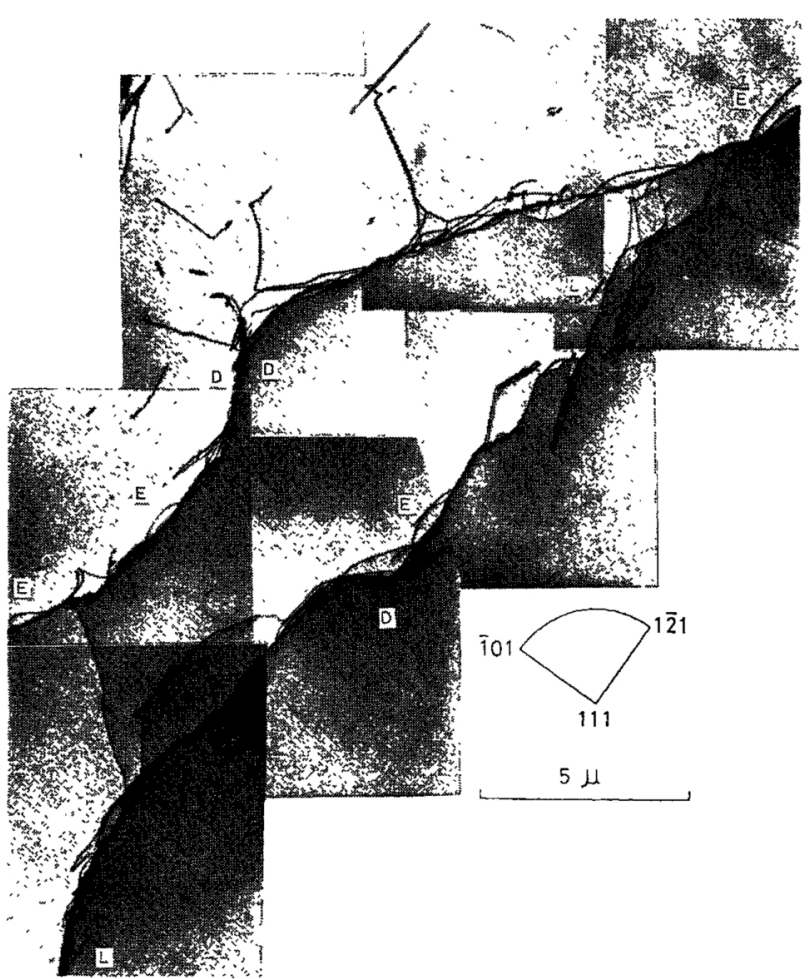

Photo. 4 Transmission electron micrograph showing dislocations in the vicinity of the sub-boundaries. The letters $\mathrm{E}$, $\mathrm{D}$ and $\mathrm{L}$ have the same meaning as in Photo. 3 . $\left\langle T=610^{\circ} \mathrm{C}, \quad \tau=340 \mathrm{~g} / \mathrm{mm}^{2}\right.$, and $\varepsilon=9.5 \%$ in steadystate creep).

photographs many dislocations (E) are observed to bow out from sub-boundaries. In order to obtain the information on the dislocation motion during creep near subboundaries, thin foils which were prepared from a crept specimen in such a way as to have almost the same crystallographic orientation as that of the original specimen (Fig. 1) were stretched inside an electron microscope. An example of the results is shown in Photo. 5. It is clearly seen that dislocations (E) bowing out from a small angle sub-boundary are emitted from it during stretching. The dislocations $E$ in Photos. 3 and 4, therefore, may be ones emitted from sub-boundaries, as pointed out by Hammand et al.(7) In Photos. 3 and 4 dislocations having dipoles (D) and dislocation loops (L) are also observed. Taking into consideration the fact that most of the slip traces are stopped at the sub-boundary as shown in Photo. 5, the presence of the dislocations $\mathrm{D}$ and $\mathrm{L}$ indicates that mobile dislocations are absorbed into the sub-boundaries and become immobile. From these observations, it is concluded that small angle sub-boundaries act as donors and recipients of mobile dislocations during high-temperature creep deformation.

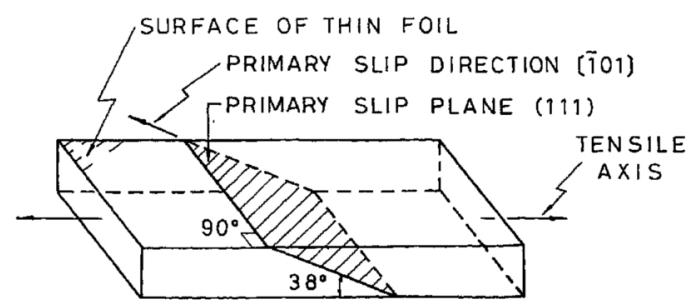

Fig. 1 A schematic representation of the orientation of the thin foils stretched in an electron microscope. 

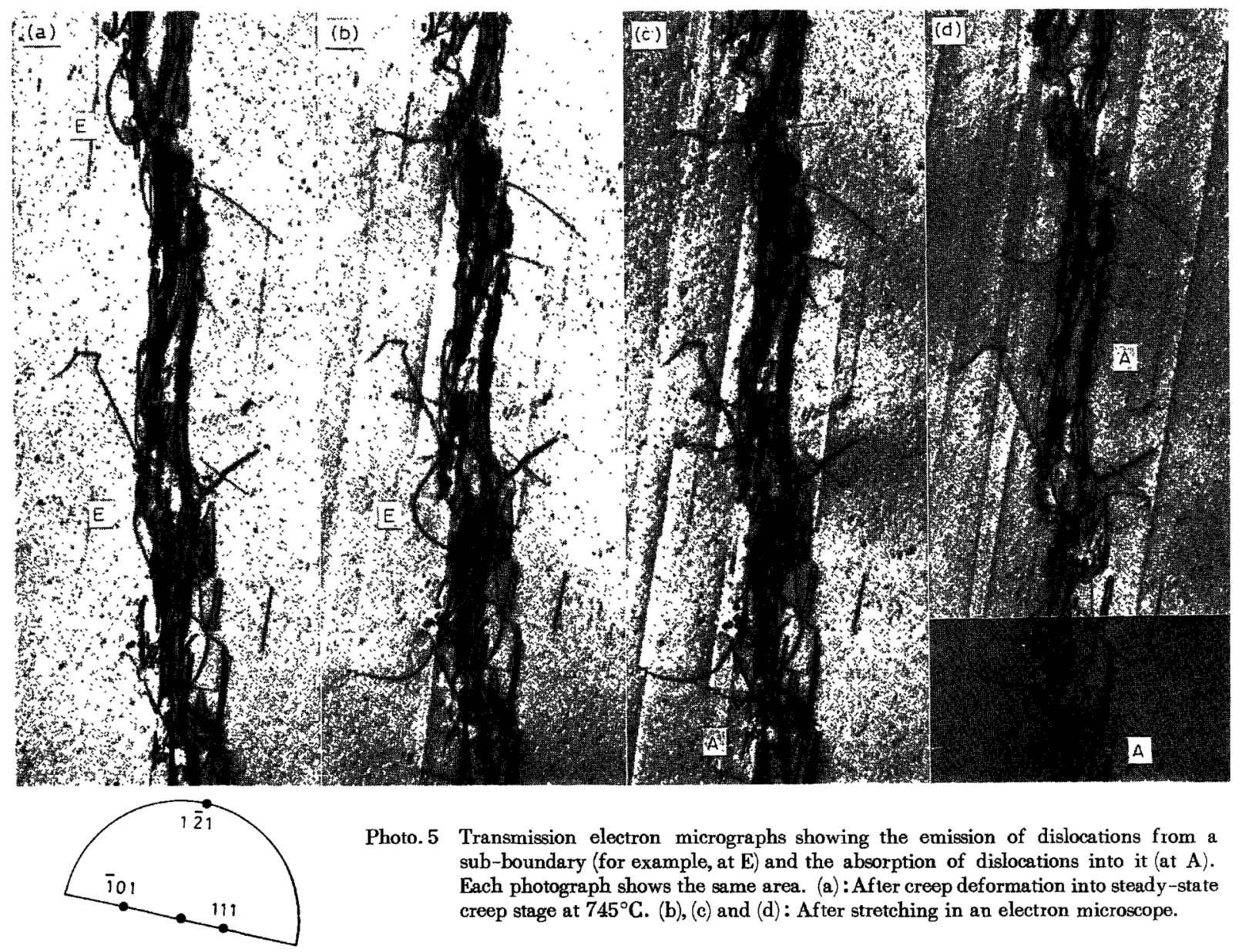

Photo. 5 Transmission electron micrographs showing the emission of dislocations from a sub-boundary (for example, at E) and the absorption of dislocations into it (at A). Each photograph shows the same area. (a): After creep deformation into steady-state creep stage at $745^{\circ} \mathrm{C}$. (b), (c) and (d): After stretching in an electron microscope.

\section{$2 \mu$}

\section{Dislocation motion in steady-state creep}

From the experimental facts mentioned above, the motion of dislocations during steady-state creep may be described as follows. In steady-state creep mobile dislocations are emitted mainly from small angle subboundaries. After gliding through subgrains, mobile dislocations are absorbed into the neighbouring small angle sub-boundaries and become immobile. The mean free path of the mobile dislocations is thus limited by small angel sub-boundaries as pointed out by $\operatorname{Stein}^{(13)}$. Therefore, the steady-state creep rate is not affected so much by large angle sub-boundaries detected by the BergBarrett method $^{(9)}$ and the etch-pit technique ${ }^{(10)}$. As seen in Photos. 2 and 4, subgrains surrounded by small angle sub-boundaries elongate in the direction of $[1 \overline{2} 1]$, in the same way as those surrounded by large angle subboundaries $^{(9)}$. The mean free path of the mobile dislocations, therefore, is a few $\mu$ to $10 \mu$ and $10 \mu$ to a few tens of microns for the primary edge and the primary screw dislocations, respectively.

\section{Steady-state creep rate}

Two dislocation theories for high temperature creep of pure metals are widely accepted : the dislocation climb theory ${ }^{(14)(15)}$ based on the climb of edge dislocations from

(13) C. Stein : J. Metals, 20 (1968), 62 A.

(14) J. Weertman : J. Appl. Phys., 26 (1955), 1213.

(15) J. Weertman : J. Appl. Phys., 28 (1957), 362. pile-up arrays and the dislocation glide theory ${ }^{(16) \sim(19)}$ based on the motion of jogged screw dislocations. In this section, these two theories are examined closely on the basis of the experimental results obtained by structure observations.

\section{(1) Dislocation climb theory}

In the present experiments thin foils with the primary slip plane, (111), parallel to the plane of the foil were examined. These foils are the ones best fit to distinguish dislocation pile-ups on the primary slip plane. As seen in Photos. $1 \sim 4$, however, the dislocation pile-ups have not been observed near sub-boundaries or within subgrains. Similar results have been reported on iron ${ }^{(1)}$, molybdenum $^{(8)}$ and copper ${ }^{(10)(20)}$. Therefore, the dislocation climb model is not adequate for the creep mechanism of pure metals.

\section{(2) Jogged screw dislocation theory}

Mukherjee et al. ${ }^{(21)}$ have recently proposed that the

(16) N. F. Mott : Creep and Fracture of Metals ab High Temperatures, N. P. L. Symposium, (1956), p. 21.

(17) P. Feltham : Acta Technica, 39(1962), 243.

(18) J. E. Dorn and J.D. Mote : High Temperature Structures and Materials, Pergamon Press, (1964), p. 95.

(19) C. R. Barrett and W.D. Nix : Acta Met., 13 (1965), 1247.

(20) S. Karashima, H. Oikawa and T. Hasegawa : J. Japan Inst. Metals, 31 (1967), 782.

(21) A. K. Mukherjee, J.E. Bird and J.E. Dorn : Trans. ASM, 62 (1969), 155. 
glide motion of jogged screw dislocations is not ratecontrolling in high temperature creep. One of the basic reasons to discard the screw dislocation model comes from the experimental results on molybdenum single crystals reported by Clauer ${ }^{(8)(22)}$. He found by transmission electron microscopy that most of the dislocations both within subgrains and in sub-boundaries are edge dislocations after creep deformation.

In copper single crystals, however, many screw dislocations were observed within subgrains after creep $^{(23)}$, though most of the sub-boundaries were parallel to the (101)-trace and were thought to be tilt boundaries consisting largely of edge dislocations. This fact implies that the motion of jogged screw dislocations is one of the possible rate-controlling process in high temperature creep. As shown below, steady-state creep rates are explained quantitatively by the glide motion of screw dislocations having super jogs.

When the glide motion of jogged screw dislocations is rate-controlling, the steady-state creep rate, $\dot{\varepsilon}$, is repre- sented by the following equation ${ }^{(18)}$.

$$
\dot{\varepsilon}=\frac{\varphi \rho b^{2} \nu(z-1)}{n} \cdot \exp \left(-\frac{Q_{s d}}{k T}\right) \cdot \exp \left(\frac{l_{j} b^{2} \tau^{*}}{n k T}\right),
$$

where

$\varphi=$ the constant depending on crystal orientation,

$\rho=$ the mobile dislocation density,

$b=$ the Burgers vector,

$\nu=$ the Debye frequency,

$z=$ the coordination number,

$Q_{s d}=$ the activation energy for self-diffusion,

$k=$ the Boltzmann's constant,

$T=$ the test temperature in degrees Kelvin,

$n=$ the jog height divided by $b$,

$l_{j}=$ the jog spacing on dislocation lines, and $\tau^{*}=$ the effective stress.

The values of the parameters other than $n, l_{j}$, and $\tau^{*}$ are known; $\dot{\varepsilon}=0.03 \% / \mathrm{hr}\left(\right.$ at $745^{\circ} \mathrm{C}$ ) or $0.005 \% / \mathrm{hr}$ (at $\left.610^{\circ} \mathrm{C}\right), \varphi=0.5^{\dagger}, \rho=3 \times 10^{6} / \mathrm{cm}^{2}\left(\right.$ at $745^{\circ} \mathrm{C}$ ) or $5 \times 10^{6}$ /

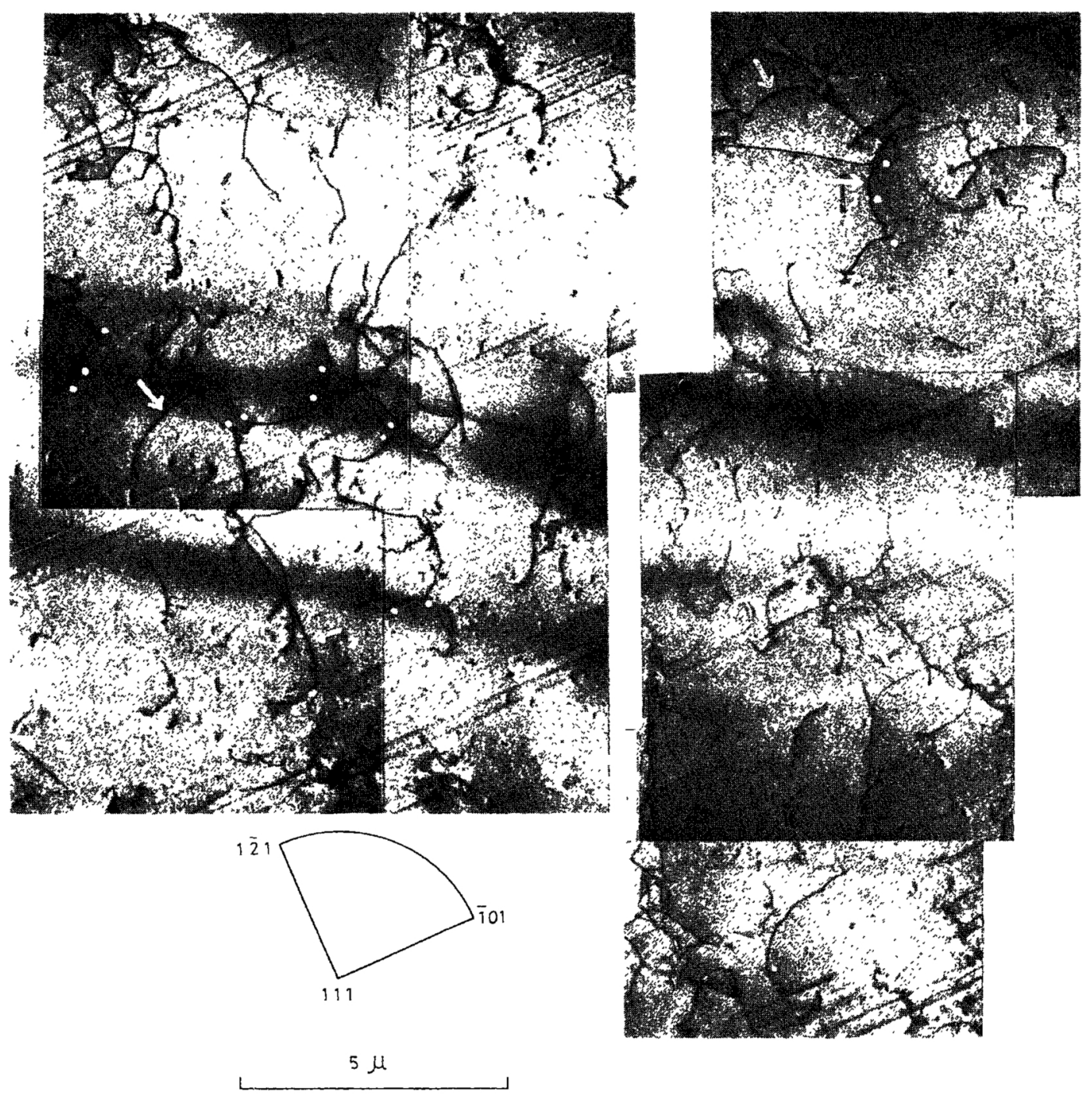

Photo. 6 Transmission electron micrographs showing the dislocation distribution within subgrains. Effective stresses were estimated from the radii of curvature of the curved dislocations indicated by arrows (see the text). Jog spacings were determined on the assumption that jogs exist on the dislocation lines at the points indicated by white dots $\left(T=745^{\circ} \mathrm{C}, \tau=180 \mathrm{~g} / \mathrm{mm}^{2}\right.$, and $\varepsilon=10.6 \%$ in steady-state creep $)$.

(22) A. H. Clauer : Trans. ASM, 61(1968),701.

(23) T. Hasegawa and S. Karashima : Met. Trans., 1 (1970), 1052. $t$ In the specimens used in the present experiments, $\gamma=2 \varepsilon$, where $\gamma$ and $\epsilon$ are the shear strain and the tensile strain, respectively. 
$/ \mathrm{cm}^{2}$ (at $610^{\circ} \mathrm{C}$ ), $b=2.55 \AA, \nu=6.56 \times 10^{12} / \mathrm{sec}, z=12$, and $Q_{s d}=49.56 \mathrm{kcal} / \mathrm{mol}^{(24)}$. In the present experiment, the jog spacing, $l_{j}$, and the effetive stress, $\tau^{*}$, are measured from transmission electron micrographs, and jog height, $n$, is calculated from equation (1).

Dislocation arrangements within subgrains in the specimen after creep at $745^{\circ} \mathrm{C}$ to $10.6 \%$ strain (in steadystate creep) are shown in Photo. 6. Isolated long dislocations in the photographs may be ones belonging to the primary slip system and lying on the primary slip plane, (111). Assuming that jogs exist on the dislocation lines at the points indicated by white dots, where dislocation lines show discontinuity or form cusps, the jog spacing, $l_{j}$, was measured ${ }^{\dagger}$ on transmission electron micrographs. The total number of measurements was about 100 , the total area of the photographs examined being about $1000 \mu^{2}$. The distribution of $l_{j}$ obtained on the specimens after creep at $745^{\circ} \mathrm{C}$ is given in Fig. 2. The average value, $\left(l_{j}\right)_{a v}=0.4 \mu$, will be used in the following discussion. In the same way the average value, $\left(l_{j}\right)_{a v}=$ $0.2 \mu$, was obtained for creep deformation at $610^{\circ} \mathrm{C}$.

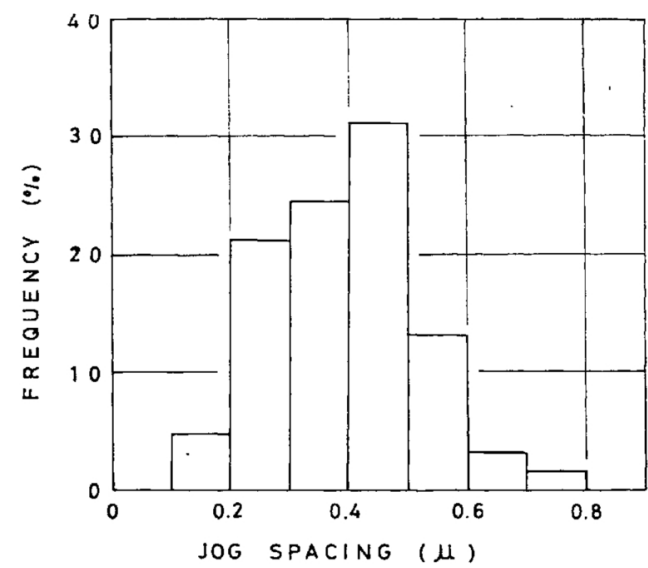

Fig. 2 Histogram of jog spacings on the dislocations within subgrains $\left(T=745^{\circ} \mathrm{C}, \tau=180 \mathrm{~g} / \mathrm{mm}^{2}\right.$, and $\varepsilon$ in steady-state creep).

Let us now discuss the effective stress, $\tau^{*}$. In general, $\tau^{*}$ is given by $\tau-\tau_{i}$, where $\tau$ and $\tau_{i}$ are the external and the internal stress, respectively. At present, however, the method of determination of $\tau^{*}$ has not been established. In the present experiments, $\tau^{*}$ was estimated on the two assumptions mentioned below.

(a) Radii of curvature, $r$, of dislocations were measured on the curved dislocations, such as the ones indicated by arrows in Photo. 6. The total number of measurements was about 70 and the total area of the photographs examined was about $1000 \mu^{2}$. The results obtained after creep at $745^{\circ} \mathrm{C}$ are given in Fig. 3 . Using the average value of $r_{a v}=4.8 \mu$ the stress, $\tau_{1}$, acting on the dislocation line is calculated from the equation $\tau_{1}=G b / 2 r(G$ :

$\uparrow \quad$ The measurement of jog spacings was made on dislocation lines having relatively large screw component.

tt The Young's modulus, $E$, is $8300 \mathrm{~kg} / \mathrm{mm}^{2}$ at $745^{\circ} \mathrm{C}^{(25)}$. The shear modulus, $G$, was calculated from the equation, $G=E$ $/ 2(1+\nu)$, where $\nu$ is the Poisson's ratio $(\nu=0.34)$.

(24) W. L. Mercer : cited by Le Claire in Phil. Mag., 7 (1962), 141.

(25) W. Köster : Z. Metallk., 39 (1948), 1. the shear modulus, $\left.3100 \mathrm{~kg} / \mathrm{mm}^{2 \dagger \dagger}\right)$. Thus, $\tau_{1}$ is estimated at $82 \mathrm{~g} / \mathrm{mm}^{2}$. On the assumption that the observed curvature of dislocations is caused by the effective stress, $\tau^{*}$, in creep deformation, one obtains that $\tau^{*}=\tau_{1}=82 \mathrm{~g}$ $/ \mathrm{mm}^{2}$.

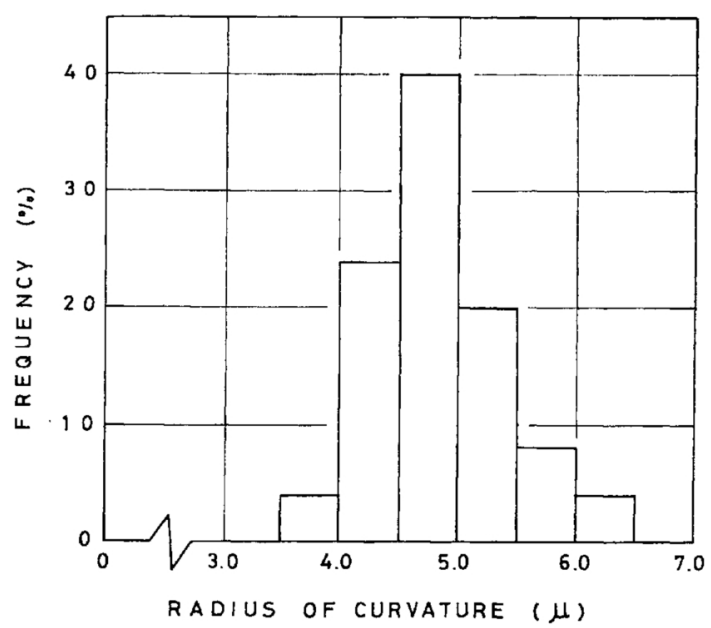

Fig. 3 Histogram of radii of curvature of the dislocation lines within subgrains $\left(T=745^{\circ} \mathrm{C}, \tau=180 \mathrm{~g} / \mathrm{mm}^{2}\right.$, and $\varepsilon$ in steady-state creep).

(b) Although the specimens were cooled to room temperature under load as rapidly as possible, thin foils were prepared from the unloaded bulk specimens. There is a possibility, therefore, that the observed curvature of dislocations is caused by the internal stress, $\tau_{i^{-}}$. In this case $\tau_{1}$ corresponds to the internal stress. Being given by $\tau^{*}=\tau-\tau_{1}$, the effective stress is estimated at $98 \mathrm{~g} / \mathrm{mm}^{2}$ $\left(=180 \mathrm{~g} / \mathrm{mm}^{2}-82 \mathrm{~g} / \mathrm{mm}^{2}\right)$.

As shown above, $\tau^{*}$ is estimated at about one half of $\tau$ on both of the assumptions. In the following discussion, therefore, the values of $90 \mathrm{~g} / \mathrm{mm}^{2}$ and $170 \mathrm{~g} / \mathrm{mm}^{2}$ will be used for the effective stress at $745^{\circ} \mathrm{C}$ and at $610^{\circ} \mathrm{C}$, respectively.

(i) In the case where the motion of screw dislocations having elementary jogs $(n=1)$ is rate-controlling

When the glide motion of screw dislocations having elementary jogs is rate-controlling, the steady-state creep rate, $\dot{\varepsilon}$, is represented by

$$
\dot{\varepsilon}=\varphi \rho b^{2} \nu(z-1) \cdot \exp \left(-\frac{Q_{s d}}{k T}\right) \cdot \exp \left(\frac{l_{j} b^{2} \tau^{*}}{k T}\right) .
$$

Putting the appropriate values shown in the foregoing paragraph into the parameters in eq. (2), the values of $\dot{\varepsilon}=3.0 \% / \mathrm{hr}$ and $\dot{\varepsilon}=1.4 \times 10^{-1} \% / \mathrm{hr}$ are obtained for the steady-state creep at $745^{\circ} \mathrm{C}$ and $610^{\circ} \mathrm{C}$, respectively. However, these values are significantly larger than the observed steady-state creep rates, $3 \times 10^{-2} \% / \mathrm{hr}\left(\right.$ at $745^{\circ} \mathrm{C}$ ) and $5 \times 10^{-3} \% / \mathrm{hr}\left(\right.$ at $\left.610^{\circ} \mathrm{C}\right)$. Therefore, the assumption that $l_{j}$ is a spacing of elementary jogs is not adequate to explain the observed creep rates on the basis of jogged screw dislocation model. 
(ii) In the case where the motion of screw dislocations having super jogs $(n>1)$ is rate-controlling

Now let us examine whether or not the observed steady-state creep rate is explained from the glide motion of screw dislocations having super jogs.

When the glide motion of screw dislocations having super jogs is rate-controlling, the steady-state creep rate, $\dot{\varepsilon}$, is represented by eq. (1). Using values of parameters mentioned before, the values of $n=21$ and $n=6$ are obtained at $745^{\circ} \mathrm{C}$ and $610^{\circ} \mathrm{C}$, respectively. Hirsch et al. ${ }^{(26)}$ have explained the flow stresses in aluminium and copper at high temperatures supposing that the glide motion of screw dislocations having super jogs of $1 \sim$ $5 \mathrm{~b}$ in height is the rate-controlling process. Watanabe and one of the present authors $(\mathrm{S} . \mathrm{K} .)^{(27)}$ have proposed that, on the basis of the measurement of activation volumes by stress relaxation tests during creep, the glide motion of screw dislocations having super jogs (10 20 b in height) is the rate-controlling process in high temperature creep of alpha iron. Experimental results have also shown that the jog height tends to become smaller with lowering test temperature and increasing applied stress ${ }^{(27)}$. Taking these facts into consideration the values of $n$ obtained here are considered to be reasonable.

In tensile tests of copper single crystals at temperatures up to $1027^{\circ} \mathrm{C}$, the values of $l_{j}=3 \sim 7 \mu$ have been reported $^{(28)}$. It has been reported that the jog spacing tends to become smaller with lowering test temperature ${ }^{(27)}$. Hence, the values of $l_{j}=0.4 \mu$ at $745^{\circ} \mathrm{C}$ and $l_{j}=0.2 \mu$ at $610^{\circ} \mathrm{C}$ obtained in the present experiments seem reasonable.

As mentioned above, the observed steady-state creep rates can be explained almost quantitatively from the glide motion of screw dislocations having super jogs. This fact supports the jogged screw dislocation model for the rate-controlling mechanism in high temperature creep.

The jogged screw dislocation model has been widely accepted by many investigators for the rate-controlling mechanism in high temperature creep ${ }^{(16) \sim(19)(27)}$. The

(26) P. B. Hirsch and D. H. Warrington : Phil. Mag.,6(1961),735.

(27) T. Watanabe and S. Karashima : Trans. JIM, 11 (1970), 159.

(28) P. C. J. Gallagher : Phil. Mag.,15(1967),51. validity of this model has for the first time been confirmed by structure observations in the present experiment. Further detailed studies, however, are needed to make clear the formation process of the super jogs.

\section{Summary}

Dislocation arrangements in copper single crystals after creep deformation at high temperatures were investigated by means of transmission electron microscopy. The dislocation motion and the creep rate in steady-state creep were discussed on the basis of the results obtained by structure observations. The main conclusions are as follows :

(1) Subgrains surrounded by large angle sub-boundaries observed by the Berg-Barrett method and the etchpit technique are further divided into smaller ones by small angle sub-boundaries which can be detected only by transmission electron microscopy.

(2) The apparent lattice twisting of the (111)-plane about the $[1 \overline{2} 1]$-axis observed by the Berg-Barrett method is caused by a random distribution of the small angle sub-boundaries.

(3) In steady-state creep mobile dislocations are emitted mainly from small angle sub-boundaries. After gliding through subgrains, mobile dislocations are absorbed into the neighbouring small angle sub-boundaries and become immobile. The mean free path of the mobile dislocations is thus limited by small angle sub-boundaries, being a few $\mu$ to $10 \mu$ and $10 \mu$ to a few tens of microns for the primary edge and the primary screw dislocations, respectively.

(4) Steady-state creep rates can be explained quantitatively from the results by transmission electron microscopy, on the assumption that the glide motion of screw dislocations having super jogs is the rate-controlling process. The heights of the super jogs are $\sim 20 \mathrm{~b}$ and $\sim 6 \mathrm{~b}$ and their spacings are $\sim 0.4 \mu$ and $\sim 0.2 \mu$ at $745^{\circ} \mathrm{C}$ and $610^{\circ} \mathrm{C}$, respectively.

\section{Acknowledgment}

One of the authors (T. H.) wishes to thank Sakkokai for the fellowship. 